\title{
Screening for bacteriuria: Microstix and dipslides
}

\author{
J. M. T. HAMilton-Miller \\ Ph.D., M.R.C.Path. \\ S. J. D. BRoOKS \\ M.B., M.R.C.P. \\ W. BRUMFITT \\ M.D., F.R.C.P. \\ M. BAKHTIAR
M.Sc.
}

Department of Medical Microbiology, Royal Free Hospital, London NW3

\begin{abstract}
Summary
The Microstix system has been tested, in parallel with dipslides, for suitability as a screening technique for the detection of bacteriuria. Results obtained using each method on 228 urine specimens were assessed by comparison with the results of quantitative counts. Dipslides had a higher sensitivity $(86.7 \%)$ than Microstix. The best specificity $(100 \%)$ was obtained from those results $(77.6 \%)$ where both components of the Microstix system were in agreement. Advantages of Microstix are its greater shelf-life and its compactness.
\end{abstract}

\section{Introduction}

Screening for bacteriuria constitutes an essential part of ante-natal care, and some, although not all, authorities consider similar screening to be worthwhile in girls of school and pre-school age as well (Asscher et al., 1973; Kunin et al., 1976). Despite the introduction over the years of several ingenious techniques for the detection of significant bacteriuria, there is no entirely satisfactory rapid test which can be carried out under conditions where there are few or no laboratory facilities (Brumfitt, Percival and Williams, 1973). The closest approach attained so far is probably the dipslide; although this is accurate, it is bulky, somewhat fragile (the agar is not infrequently detached when it is posted) and has a short shelf-life (4 months). In a new development, Microstix (Ames), an attempt is made to resolve these shortcomings. It is not yet entirely clear, however, how accurate this device is, as there are only a few, conflicting, reports on its use (Craig, Kunin and Degroot, 1973; Gillenwater, 1975; Winter, 1975; Duerden and Moyes, 1976). Because of the potential importance of this invention for use in screening programmes such as those mentioned above, as well as for the detection of significant bacteriuria in the general practitioner's surgery, an

Correspondence: Professor W. Brumfitt, Department of Medical Microbiology, Royal Free Hospital, Pond Street, London NW/3 2QG. assessment was undertaken of its performance, in parallel with the established dipslide method (Rich, Glass and Selkon, 1976). The two screening methods were compared with a method which gives quantitative counts.

\section{Materials and methods \\ Urine specimens}

Two hundred and twenty-eight freshly voided urines, obtained either from patients attending the Renal Polyclinic or sent to the diagnostic section of the department, were tested by both methods. Formal quantitative counts were also carried out in order that an accurate assessment of the results could be made

\section{Microstix}

Each test strip bears three pads: nitrite is identified by a modification of the Griess test on one, and the other two are composed of dehydrated culture medium and 2,3,5-triphenyltetrazolium chloride (TTC). One contains brain/heart infusion alone and the other contains sodium desoxycholate in addition. Bacterial growth is detected by the appearance of small dark-red spots on these culture pads, and quantification can be made by comparison with a chart supplied by the manufacturers. The nitrite pad is read within seconds of the strip being dipped into urine, the culture pads after overnight incubation in a special plastic pouch provided.

In this study, numbers of bacteria present were estimated, by reference to the chart provided by the manufacturers, as $>10^{5}, 10^{5}, 10^{4}, 10^{3}$ or $<10^{2}$.

\section{Quantitative counts}

Urines were diluted $1: 10$ and $1: 100$ in sterile saline, and $0.1 \mathrm{ml}$ samples of these and of undiluted urine were spread over the surface of plates containing cystine-lactose-electrolyte-deficient (CLED) agar (Oxoid). Colony counts were made after overnight incubation at $37^{\circ} \mathrm{C}$, and results were rounded to the nearest power of 10 , so that comparison could be made with the Microstix results. 


\section{Dipslides}

Oxoid dipslides, coated on one side with CLED agar and on the other with MacConkey agar, were used. Slides were read, after overnight incubation, by reference to the manufacturer's instructions.

\section{Analysis}

For each urine specimen, the results obtained with Microstix (number of bacteria and presence or absence of nitrite), dipslide (number of bacteria) and by quantitative count were recorded. Concentrations of bacteria $\geqslant 10^{5} / \mathrm{ml}$ were designated 'significant', $10^{4}$ or $10^{3} / \mathrm{ml}$ 'doubtful' (another specimen was requested in these cases) and $\leqslant 10^{2} / \mathrm{ml}$ 'not significant'. For the purposes of this analysis, a positive nitrite test was taken to indicate $\geqslant 10^{5}$ organisms/ $\mathrm{ml}$, a negative test $<10^{5} / \mathrm{ml}$.

In making comparisons between the results, the quantitative count was taken as the accurate 'standard'. The quantitative count was compared with the following: (a) Microstix, culture only; (b) Microstix, nitrite only; (c) combined results of the Microstix test, if these were in agreement (namely $\geqslant 10^{5}$ bacteria per $\mathrm{ml}$ and nitrite positive, or $<10^{5}$ bacteria per $\mathrm{ml}$ and nitrite negative). Such agreement was obtained in 177 of the 228 specimens $(77.6 \%)$; (d) dipslide culture.

The numbers of false-positive (FP) and false negative (FN) results were calculated for each situation, and these figures used to work out the statistical parameters, sensitivity, specificity and predictive values, for positive and negative results (Krieg, Gambino and Galen, 1975).

In situations (a) and (d), where quantitative results had been obtained, regression analyses were carried out.

\section{Results}

Quantitative count v. Microstix culture

The unprocessed data are shown in Table 1. From this it is apparent that, although virtually exact agreement was apparently obtained on the number of specimens containing 'significant' numbers of bacteria, some $40 \%$ of the 'doubtful' results have been transferred to the 'not significant' category by the Microstix results. It is clear, then, that the Microstix technique tends to underestimate the number of bacteria. Detailed analysis showed that bacterial counts coincided by the two methods in 147 specimens, while in fifty-six cases the quantitative count was greater than that assessed by Microstix, and vice versa in only twenty-five cases. FN results (thirty-four) considerably outnumbered FP (fifteen). For this test the sensitivity was $65.3 \%$, specificity $88.5 \%$, the predictive value for a positive result $81 \%$ and for a negative result $77 \cdot 2 \%$.

\section{Quantitative count $\mathrm{v}$. Microstix nitrite}

Only twenty-two of the urine samples gave a positive result for nitrite (separate tests showed that the lower limit of detection of sodium nitrite by this technique was $10 \mu \mathrm{g} / \mathrm{ml}$ ). Only twelve of these twentytwo urines contained 'significant' numbers of bacteria; thus, a positive result in this test is virtually useless, as the sensitivity is only $24.5 \%$ and the predictive value of a positive result $54.5 \%$. However, a negative result is of more use in excluding urinary-tract infection: the specificity of the test was $94.4 \%$ and the predictive value of a negative test was $82 \%$.

\section{Quantitative count v. Microstix combined results}

This comparison reveals no FP results; the

TABLE 1. Results obtained by five methods. Figures in parentheses are those individual cases in agreement with the quantitative count

\begin{tabular}{lccc}
\hline & \multicolumn{3}{c}{ Bacterial concentration } \\
\cline { 2 - 4 } Method of assessment & $\begin{array}{c}\text { Significant } \\
\left(\geqslant 10^{5} / \mathrm{ml}\right)\end{array}$ & $\begin{array}{c}\text { Doubtful } \\
\left(10^{4} \text { and } 10^{3} / \mathrm{ml}\right)\end{array}$ & $\begin{array}{c}\text { Not significant } \\
\left(<10^{2} / \mathrm{ml}\right)\end{array}$ \\
\hline Quantitative culture & 49 & 56 & 123 \\
Microstix culture & 50 & 34 & 144 \\
Dipslide & $(42)$ & $(23)$ & $(115)$ \\
& 54 & 52 & 122 \\
& $(43)$ & $(35)$ & $(113)$ \\
\hline
\end{tabular}

\begin{tabular}{lcc}
\hline & $\begin{array}{c}\text { Significant } \\
\left(\geqslant 10^{5} / \mathrm{ml}\right)\end{array}$ & $\begin{array}{c}\text { Not significant } \\
\left(<10^{5} / \mathrm{ml}\right)\end{array}$ \\
\hline Quantitative culture & 49 & 179 \\
Microstix, nitrite only & 22 & 206 \\
& $(12)$ & $(169)$ \\
Microstix, combined & 21 & 156 \\
& $(12)$ & $(156)$ \\
\hline
\end{tabular}


specificity and the predictive value for a positive test are therefore $100 \%$. The sensitivity however, is still low $(57 \cdot 1 \%)$. The small number of FN results (nine) means that the predictive value of a negative result is as high as $94.5 \%$.

\section{Quantitative count v. dipslide}

In contrast to the Microstix culture method, dipslides tended to overestimate bacterial counts. There was precise numerical agreement in 148 individual cases, and a higher count was obtained by dipslide than by quantitative count in fifty-seven specimens and the reverse in twenty-three. As a consequence, FP results (twenty-five) occurred about twice as often as did FN (twelve). The sensitivity of this method, $86.7 \%$, was the highest recorded in this study, but the specificity $(81.2 \%)$ and the predictive value for a positive result $(75.7 \%$ ) were lower than the corresponding figures for Microstix culture alone or combined results.

\section{Regression analysis}

There was a better linear relationship between counts for quantitative count $v$. dipslides $(r=0.876)$ than for quantitative count $v$. Microstix count $(r=0.82)$, but the fit was excellent in each case. The slopes of both regression lines were very close to unity.

\section{Discussion}

In screening for bacteriuria of pregnancy a FN result could be disastrous. It is well established (Kass, 1960; Condie et al., 1968) that this condition, if untreated, leads in about $20 \%$ of cases to acute pyelonephritis. A FP result, on the other hand, although undesirable, is not so serious, provided it is a relatively rare occurrence, as the patient can be recalled and a further properly taken mid-stream specimen of urine examined. Bearing this in mind, the present results show that the dipslide performs better than either part of the Microstix alone, but not as well as the combination of the two parts of Microstix. This latter test not only gave no FN, but also produced the lowest level of FP results.

Microstix are less fragile and more compact than dipslides, but their main advantage seems to be their much longer shelf-life. Owing to the small size of the culture pad they are not as easy to read as dipslides. In cost, Microstix are slightly more expensive at the time of writing (November 1976).

The Microstix technique has a major disadvantage from a purely laboratory point of view in that organisms are not easy to isolate directly from the pads of medium. This is presumably because colonies form in the depth of the medium, since they are difficult to subculture from the surface. To be certain of isolating the organism, all or part of the pad would have to be subcultured in broth.
Other factors which are against the easy isolation of colonies are firstly, the possibility that a component toxic to bacteria used in the Griess reaction (e.g. $p$-arsanilic acid) may contaminate the culture pads, secondly, the smearing effect of sliding the test strip out of the tightly closed plastic pouch and, thirdly, the fact that reduction of TTC by bacteria does not occur regularly (Brumfitt, 1972). TTC may also be inhibitory: it was found that TTC at $0.3 \mathrm{mg} /$ $\mathrm{ml}$ permits the growth of coliform organisms and faecal-type streptococci (although the latter strains failed to form the deep red formazan), but inhibits most strains of staphylococci isolated from urinary tract infections. All the latter species grew at 0.03 $\mathrm{mg} / \mathrm{ml}$, but most of them produced so little formazan under these conditions that they were difficult to see. It is therefore probable that Gram-positive cocci may be either overlooked or inhibited by TTC on the culture pads of Microstix.

\section{Acknowledgment}

We are grateful to D. W. Kerry for writing a programme for the Monroe 1860 calculator.

We thank Miles Laboratories Ltd, Stoke Poges, for supplying Microstix.

\section{References}

Asscher, A.W., Mclachlan, M.S.F., Jones, R.V., Meller, S., Sussman, M., Harrison, S., Johnston, H.H., Sleight, G. \& Fletcher, E.W. (1973) Screening for asymptomatic urinary-tract infection in schoolgirls. Lancet, ii, 1.

BrumfitT, W. (1972) In: Renal Disease, 3rd edn (Ed. by D. A. K. Black), p. 367. Blackwell Scientific Publications, Oxford.

Brumfitt, W., Percival, A. \& Williams, J.D. (1973) Estimation of bacterial and white cells in the urine. A.C.P. Broadsheet 80. Association of Clinical Pathologists.

Condie, A.P., Williams, J.D., Reeves, D.S. \& BrumfitT, W. (1968) In: Urinary Tract Infection (Ed. by F. O'Grady and W. Brumfitt), p. 148. Oxford University Press, London.

Craig, W.A., Kunin, C.M. \& Degroot, J. (1973) Evaluation of new urinary tract screening devices. Applied Microbiology, 26, 196.

DUERDEN, B.I. \& MoYes, A. (1976) Comparison of laboratory methods in the diagnosis of urinary tract infection. Journal of Clinical Pathology, 29, 286.

GillenWATER, J.Y. (1975) Diagnosis of urinary tract infection: appraisal of diagnostic procedures. Kidney International, 8, S-3.

KASS, E.H. (1960) Bacteriuria and pyelonephritis of pregnancy. Archives of Internal Medicine, 105, 194.

KRIEG, A.F., GAMBINO, R. \& GALEN, R.S. (1975) Why are clinical laboratory tests performed? When are they valid? Journal of the American Medical Association, 233, 76.

Kunin, C.M., Degroot, J.E., Uehling, D. \& Ramgopal, V. (1976) Detection of urinary tract infections in 3-5-year-old girls by mothers using a nitrite strip. Pediatrics, 57, 829.

Rich, G., Glass, N.J. \& Selkon, J.B. (1976) Cost-effectiveness of two methods of screening for asymptomatic bacteriuria. British Journal of Preventive and Social Medicine, 30, 54.

WINTER, C.C. (1975) Rapid miniaturized tests for bacteriuria: Microstix and Bacturcult urine tests. Journal of Urology, 114, 735 . 